\title{
Sistem Informasi Pengelola Bank ASI Berbasis Website (Studi Kasus: Posyandu Kelurahan Bantarsoka)
}

\author{
Tyas Pratama Puja Kusuma*¹, Dania Gusmi Rahayu ${ }^{2}$ \\ ${ }^{1,2}$ Program Studi Sistem Informasi, Universitas Amikom Purwokerto \\ email: tyaspratama@amikompurwokerto.ac.id*1 ${ }^{*}$ daniagusmir@gmail.com ${ }^{2}$.
}

(Received: 30 Maret 2021/ Accepted: 20 April 2021 / Published Online: 20 Juni 2021)

\begin{abstract}
Abstrak
Permasalahan yang dibahas dalam penelitian ini adalah merancang suatu system yang dapat digunakan sebagai bank ASI. Posyandu Kelurahan Bantarsoka sangat peduli dengan pentingnya ASI bagi bayi. Banyaknya bayi yang tidak mendapatkan ASI menjadi suatu keprihatinan, di sisi lain banyak pula para ibu menyusui yang memiliki ASI berlebih. Belum adanya system yang mewadahi informasi tentang ASI di Posyandu Kelurahan Bantarsoka menjadikan Posyandu tersebut kurang maksimal dalam membantu warganya mengatasi masalah penyaluran ASI. Dengan perkembangan teknologi saat ini munculah gagasan untuk membuat suatu system informasi pengelola ASI yang nantinya dapat menjadi solusi dari permasalahan yang ada. Sistem Pengelola Bank ASI bertujuan untuk memberi wadah bagi ibu yang berlebih ASI untuk dapat mendonorkan ASInya untuk para bayi yang tidak mendapatkan asupan ASI dari ibu mereka. Penelitian ini menggunakan metode Waterfall yang dilakukan dengan pendekatan sistematis, mulai dari tahap kebutuhan system, analisis, desain, coding, testing, dan maintenance. Hasil dari penelitian ini adalah sistem informasi berupa website Bank ASI. Dengan adanya system ini, diharapkan dapat membantu permasalahan penyaluran ASI. Sistem yang dibuat ini dapat mengelola dan mendata kepemilikan ASI dengan baik, siapa pendonor dan penerimanya. Dengan memanfaatkan teknologi internet, penyebaran informasi dapat diakses dengan cepat dan mudah.
\end{abstract}

Kata kunci: Bank ASI, Donor, Sistem Informasi, Website.

\begin{abstract}
The problem discussed in this study is designing a system that can be used as an ASI bank. The Posyandu in Bantarsoka Village is very concerned about the importance of breastfeeding for babies. A lot of babies who are not breast fed are a concern. On the other hand, many breastfeeding mothers also have excess breast milk. The absence of a system that accommodates information about ASI at the Posyandu in Bantarsoka Village makes the Posyandu less optimal in helping its residents overcome the problem of breastfeeding distribution. With current technological developments, the idea emerged to create an information system for ASI management, which later could be a solution to the problems. The ASI Bank Management System aims to provide a forum for mothers who have been excess breast fed to be able to donate their breast milk to babies who do not get their mother's milk intake. This study uses the Waterfall method which is carried out with a structured approach, starting from the system requirement's stages, analysis, design, coding, testing, and maintenance. The result of this research is an information system in the form on the ASI Bank website. With this system, it is hoped that it can help with the problem of breastfeeding distribution. The system created can properly manage and record breastfeeding ownership, who is the donors and recipients. By utilizing Internet technology, information dissemination can be accessed quickly and easily.
\end{abstract}

Keywords: ASI Bank, donor, Information system, Website. 


\section{PENDAHULUAN}

ASI eksklusif adalah ASI yang diberikan kepada bayi sejak dilahirkan selama enam bulan, tanpa menambahkan dan/atau mengganti dengan makanan atau minuman lain kecuali obat, vitamin, dan mineral (Kemenkes RI, 2015). Hasil penelitian yang dilakukan pakar kesehatan menunjukkan bahwa anak yang di masa bayinya mengkonsumsi ASI jauh lebih cerdas, lebih sehat, dan lebih kuat dari pada anak yang di masa kecilnya tidak mengkonsumsi ASI. Kegagalan pemberian ASI eksklusif disebabkan oleh faktor internal dan eksternal (Fikawati \& Syafiq, 2009). Faktor internal meliputi usia, rendahnya pengetahuan ibu, sikap ibu, psikologis ibu saat menyusui, kondisi fisik ibu, ibu bekerja serta adanya kelainan anatomi payudara. Faktor eksternal meliputi kurangnya dukungan keluarga dan masyarakat, gencarnya promosi susu formula, faktor sosial budaya, kurangnya ketersediaan fasilitas pelayanan kesehatan ibu dan anak, serta dukungan tenaga kesehatan termasuk konselor ASI. Menyusui merupakan hal yang esensial bagi manusia, maka sebagian orang berpikir tentang beragam cara agar semua orang dengan segala aktivitas dapat menyusui tanpa mengganggu kinerja kerjanya. Maka para ilmuan Eropa menghadirkan ide untuk mendirikan Bank ASI dengan tujuan membantu para ibu yang tidak bisa menyusui bayinya secara langsung. Setelah berkembangnya zaman pelaku donor ASI di Indonesia dilindungi oleh Peraturan Pemerintah Nomor 33 tahun 2012 pasal 11 yang berisi persyaratan-persyaratan khusus untuk para pendonor dan penerima donor ASI, yaitu: Donor ASI dilakukan sesuai permintaan ibu kandung atau keluarga bayi yang bersangkutan, Identitas, agama dan alamat pendonor ASI diketahui jelas oleh ibu kandung atau keluarga bayi penerima ASI, Mendapat persetujuan pendonor ASIsetelah mengetahui identitas bayi yang diberi ASI, Pendonor ASI dalam kondisi kesehatan baik dan tidak mempunyai indikasi medis. ASI tidak diperjual belikan.

Menurut (UNICEF, 2018), sebanyak 30.000 kematian bayi di Indonesia dan 10 juta kematian balita di dunia pada tiap tahunnya dapat dicegah melalui pemberian ASI secara eksklusif. Pemberian ASI memberikan manfaat bagi bayi maupun ibu. Menurut (Egziabher \& Edwards, 2013) Pemberian ASI dapat melindungi dari perdarahan postpartum, depresi postpartum, kanker ovarium dan payudara, penyakit jantung dan diabetes tipe $2^{3}$.

Posyandu adalah Pos Pelayanan Terpadu yang berada di lingkungan masyarakat per Kelurahan. Posyandu Kelurahan Bantarsoka sangat peduli dengan pentingnya ASI bagi bayi. Banyaknya bayi yang tidak mendapatkan ASI menjadi suatu keprihatinan, di sisi lain banyak pula para ibu menyusui yang memiliki ASI berlebih. Belum adanya system yang mewadahi informasi tentang ASI di Posyandu Kelurahan Bantarsoka menjadikan Posyandu tersebut kurang maksimal dalam membantu warganya mengatasi masalah penyaluran ASI.

Pada penelitian yang dilakukan oleh (Ayuningtyas, 2018) sudah banyak masyarakat di Indonesia yang sudah memanfaatkan media sosial sebagai informasi donor ASI dan sudah adanya aplikasi yang menyalurkan antara pendonor dan penerima ASI. Dari penelitian tersebut memunculkan ide untuk membuat sistem informasi yang dapat menyalurkan pendonor dan penerima ASI. Kemudian penelitian yang dilakukan oleh (Abdullah, 2017) tentang analisis jual beli ASI menurut hukum islam. Penelitian ini digunakan sebagai acuan dalam menentukan batasan-batasan donor ASI sesuai syariat islam. Dengan adanya hal tersebut maka sistem informasi Bank ASI yang dibuat tidak menyalahi aturan donor ASI sesuai syariat Islam. Penelitian yang dilakukan oleh (Subur, Dian, \& Merry Tyas, 2012) tingkat pendidikan seorang ibu juga berhubungan dengan pengetahuan ibu dalam pemberian ASI. Penelitian tersebut berbanding lurus dangan keadaan yang terjadi di Posyandu Kelurahan Bantarsoka.

Dengan perkembangan teknologi saat ini munculah gagasan untuk membuat suatu sistem informasi pengelola ASI yang nantinya dapat menjadi solusi dari permasalahan yang ada di Posyandu Kelurahan Bantarsoka. Menurut (Fadhlurrahman \& Capah, 2020) Sistem informasi adalah cara terorganisir untuk mengumpulkan, memasukan, memproses data dan 
menyimpannya, mengelola, mengontrol dan melaporkannya sehingga dapat mendukung perusahaan atau organisasi untuk mencapai tujuan. Sejumlah peneliti juga, telah menerapkan dan bahkan mengembangkan sistem informasi yang bertujuan untuk memudahkan pekerjaan sebuah organisasi baik secara individu dan kelompok diberbagai bidang diantaranya: (Andri \& Suyanto, 2020; Apollonio et al., 2018; Muntohar, 2020; Raj \& Smys, 2019; Suprapto, Fauziah, Fitri, \& Hayati, 2020)

Berdasarkan hal tersebut di atas, sistem informasi yang akan dibuat di dalamnya dapat mendata ibu yang memiliki ASI berlebih serta bayi yang tidak mendapatkan ASI dari ibunya. Sistem Pengelola Bank ASI bertujuan untuk memberi wadah bagi ibu yang berlebih ASI untuk dapat mendonorkan ASInya untuk para bayi yang tidak mendapatkan asupan ASI dari ibu mereka. Hal tersebut mendasari bahwa penelitian ini penting untuk dilakukan.

\section{METODE}

Metode yang digunakan pada penelitian ini menggunakan metode pengembangan sistem air terjun (waterfall) yang terlihat pada gambar 1. Teknik analisis atau pengujian yang digunakan dalam penelitian ini adalah black box testing yang berfokus pada spesifikasi fungsional dari perangkat lunak (Jaya, 2018). Tahapan-tahapan dari penelitian metode waterfall menurut (Ganney, Pisharody, \& Claridge, 2013) adalah sebagai berikut:

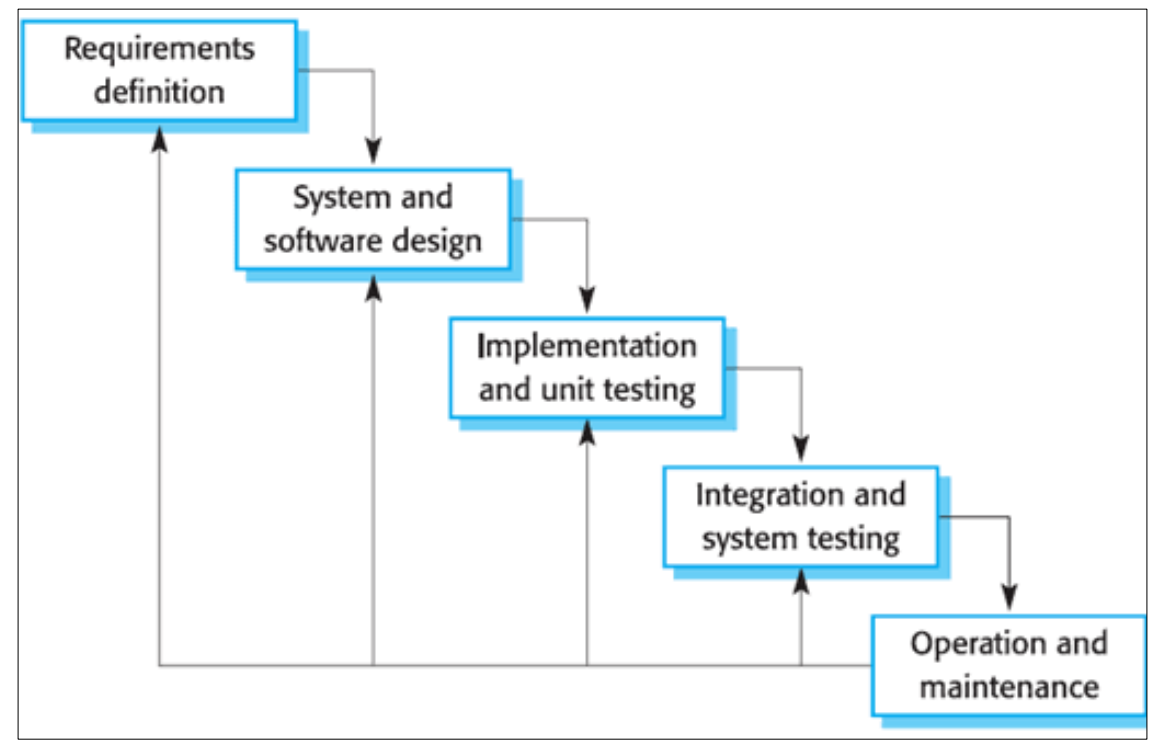

Gambar 1. Model Waterfall

\section{Requirements definition}

Tahapan di mana kendala, tujuan, serta fungsi sistem ditetapkan dari hasil konsultasi dengan pengguna yang kemudian didefinisikan secara rinci dan berfungsi sebagai spesifikasi sistem (Rizki \& Mulyati, 2020; Suprapto et al., 2020).

System and software design

Tahapan perancangan sistem, mengalokasikan kebutuhan-kebutuhan sistem baik perangkat keras maupun perangkat lunak dengan membentuk arsitektur sistem secara keseluruhan. Perancangan perangkat lunak melibatkan identifikasi dan penggambaran abstraksi sistem dasar perangkat lunak dan hubungannya.

Implementation and unit testing

Pada tahap ini, perancangan perangkat lunak diwujudkan dalam serangkaian program atau unit program. Pengujian melibatkan verifikasi bahwa setiap unit memenuhi spesifikasinya. 


\section{Integration and system testing}

Unit-unit individu program digabung dan diuji sebagai sebuah sistem lengkap untuk memastikan apakah sesuai dengan kebutuhan perangkat lunak atau tidak. Pengujian perangkat menggunakan blackbox testing. Setelah pengujian, perangkat lunak dapat dikirimkan ke customer.

\section{Operation and maintenance}

Pemasangan sistem dan digunakan secara nyata. Maintenance melibatkan pembetulan kesalahan yang tidak ditemukan pada tahapan-tahapan sebelumnya, meningkatkan implementasi dari unit sistem, dan meningkatkan layanan sistem sebagai kebutuhan baru (Hakim, Gustina, Putri, \& Faudiah, 2020; Kusrini, Fathurrahmani, \& Sayyidati, 2020) .

\section{HASIL DAN PEMBAHASAN}

\section{Hasil}

\section{Requirements definition}

Tahapan pengembangan system dimulai dengan menganalisis kebutuhan pengguna terhadap system yang akan dibangun berdasarkan hasil wawancara dengan pengguna. Dari hasil analasis tersebut kemudian didefinisikan dalam bentuk fungsi-fungsi. Kebutuhan tersebut meliputi kebutuhan untuk mendaftar sebagai anggota donor ASI, informasi donor ASI, informasi stok ASI.

\section{System and software design}

Penggambaran alur kerja sistem informasi pengolahan Bank ASI dijelaskan menggunakan use case pada gambar 2. Hasil tersebut merupakan use case diagram donor ASI yang menjelaskan fungsi dari sistem informasi pengelola Bank ASI dan siapa saja yang dapat mengakses sistem tersebut. Terdapat lima fungsi yaitu melihat stok ASI di web, registrasi, update data donor, mengisi form donor, dan rekap kegiatan donor. Terdapat tiga aktor yang dapat mengakses fungsi-fungsi tersebut. Administrator memiliki hak askses untuk menggunakan fungsi melihat stok ASI di web, update data donor, dan rekap kegiatan donor. Pendonor dapat mengakses fungsi melihat stok ASI dan registrasi. Penerima dapat mengakses fungsi melihat stok ASI, registrasi dan mengisi form donor.

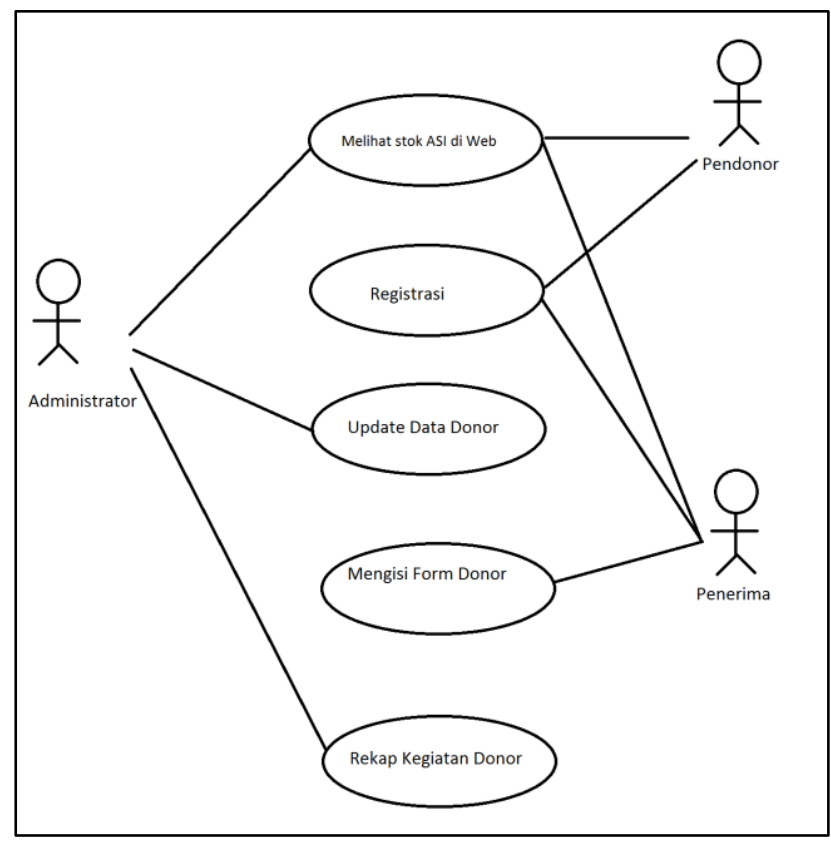

Gambar 2. Use Case Donor ASI 


\section{Implementation and unit testing}

Berikut adalah implementasi dari sistem informasi pengelola Bank ASI berbasis website yang terlihat pada gambar 3. Halaman home yang merupakan tampilan awal dari sistem informasi pengelola Bank ASI. Terdapat beberapa menu di halaman home ini, diantaranya adalah: login, explore, bantuan, tentang, dan kontak. Selanjutnya pada gambar 4 adalah halaman login admin digunakan oleh administrator untuk mengakses sistem informasi pengelola Bank ASI.

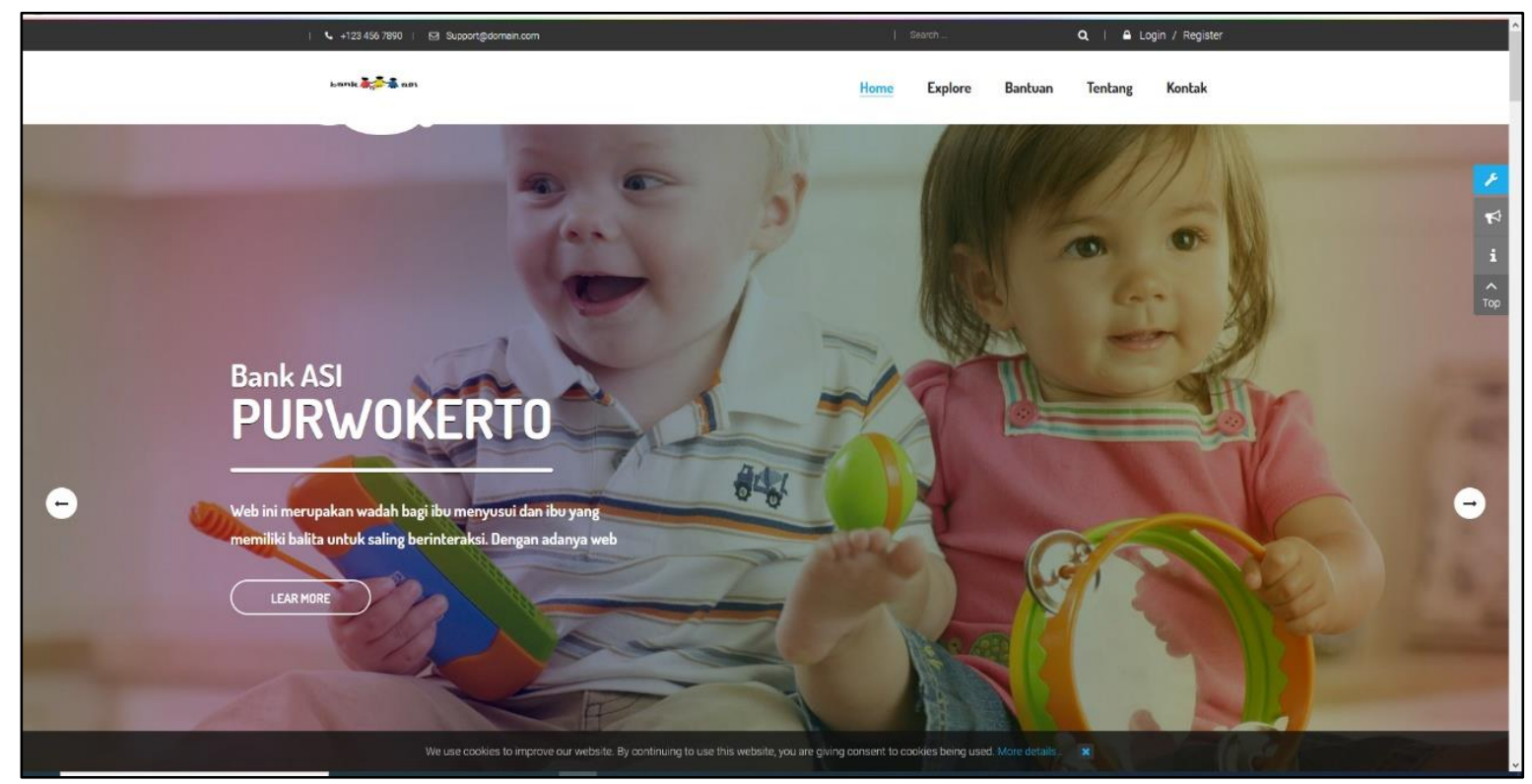

Gambar 3. Tampilan Halaman Home User

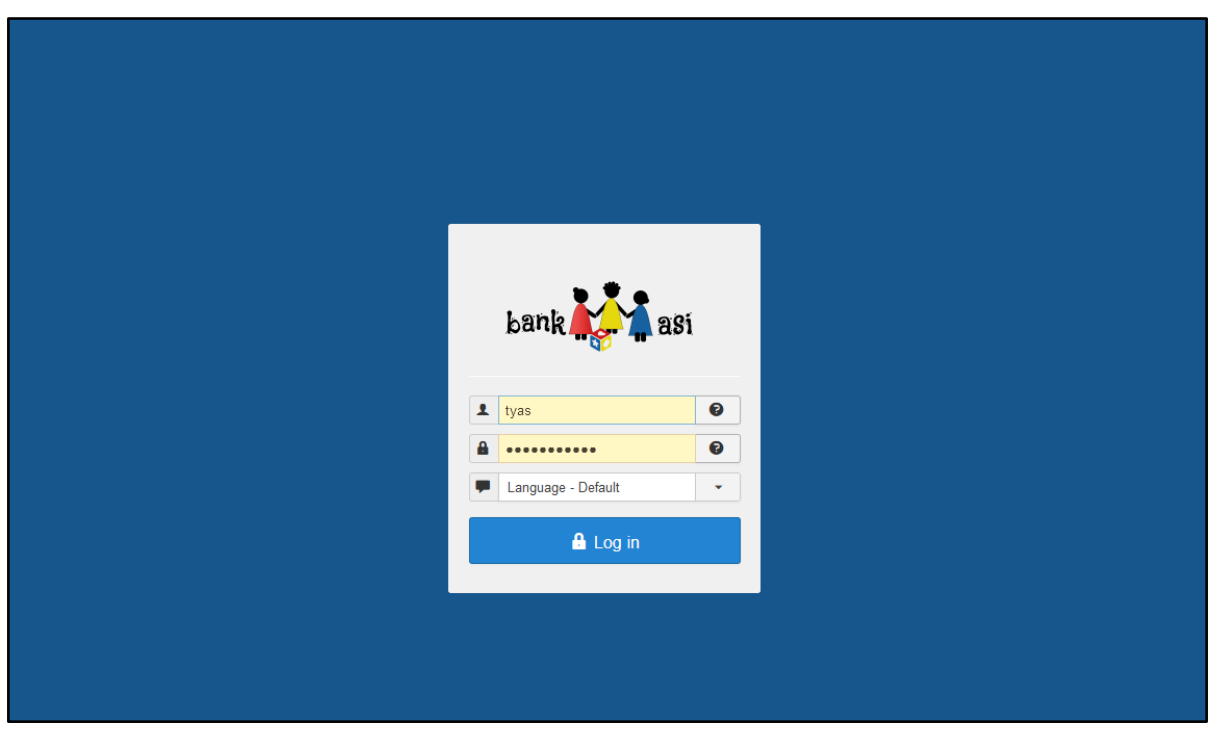

Gambar 4. Halaman Login Admin

Halaman home admin berisi beberapa menu yang dapat digunakan oleh administrator untuk menambah, mengedit, serta menghapus data donor ASI (lihat gambar 5). Sementara itu, halaman pendonor menampilkan biodata mendonor ASI yang telah terdaftar dalam system seperti yang terlihat pada gambar 6. Dan yang terakhir adalah halaman pendaftaran member digunakan oleh user yang ingin mendaftar sebagai mendonor ASI (lihat gambar 7). 


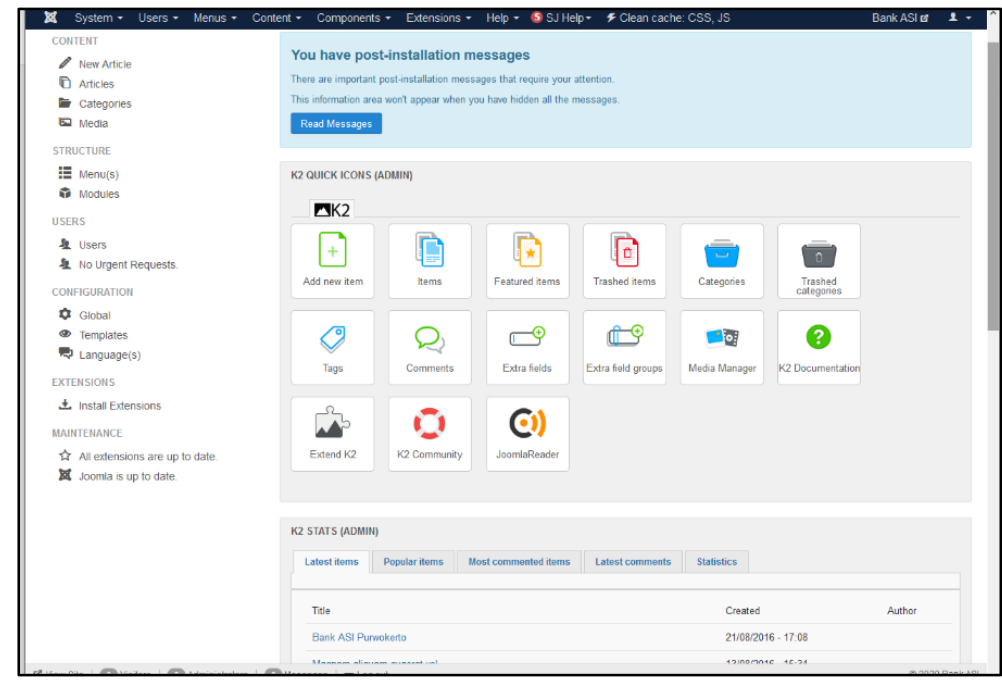

Gambar 5. Halaman Home Admin

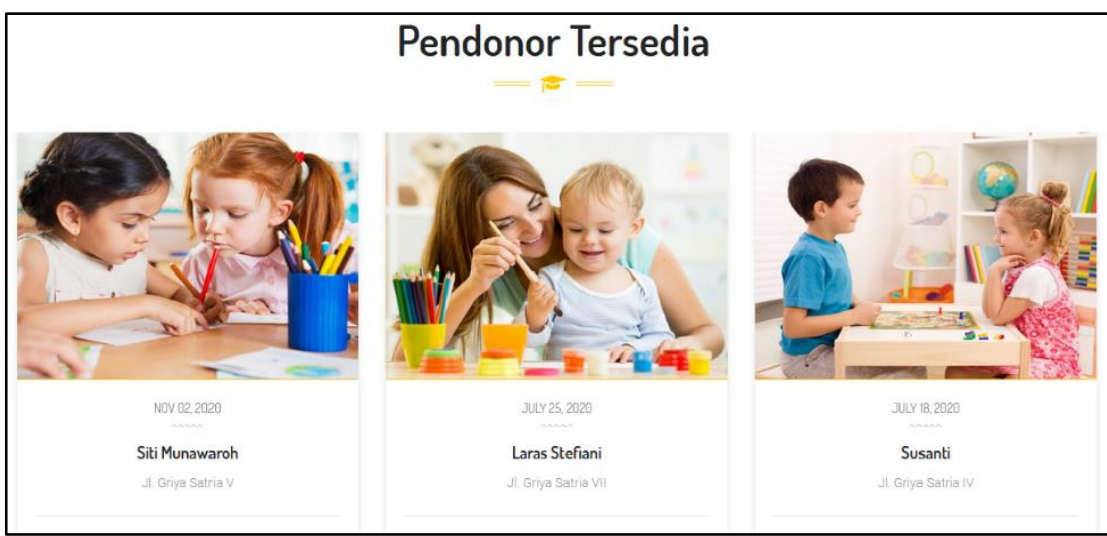

Gambar 6. Tampilan Halaman Pendonor ASI

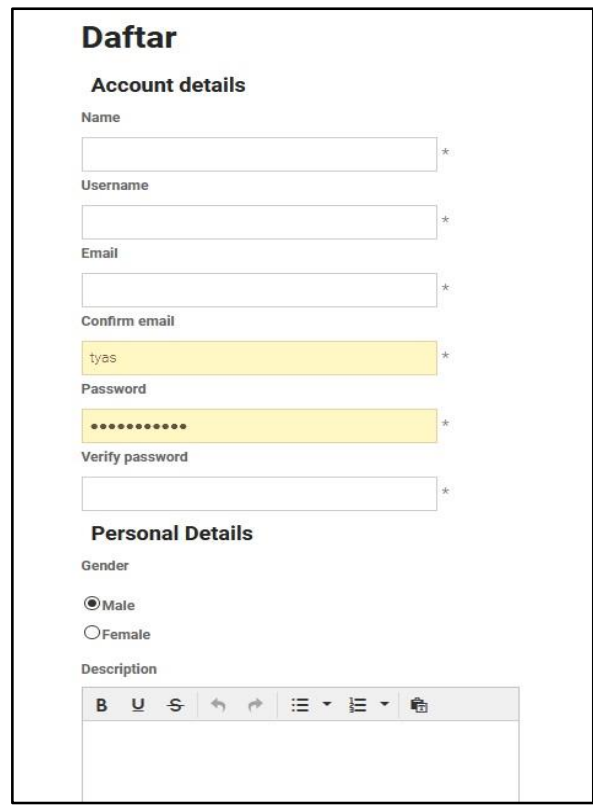

Gambar 7. Tampilan Halaman Pendaftaran Member 


\section{Integration and system testing}

Sebelum sistem didistribusikan dilakukan pengujian terlebih dahulu. Pengujian sistem dilakukan dengan cara black box testing. Setiap fungsi yang ada pada sistem diuji coba dengan skenario pengujian yang telah ditetapkan. Hasil blackbox testing dapat dilihat pada tabel 1 berikut.

Tabel 1. Hasil Black Box Testing

\begin{tabular}{|c|c|c|c|c|}
\hline $\begin{array}{c}\text { Skenario } \\
\text { Pengujian }\end{array}$ & Kasus Pengujian & $\begin{array}{c}\text { Hasil yang } \\
\text { diharapkan }\end{array}$ & $\begin{array}{c}\text { Hasil } \\
\text { Pengujian }\end{array}$ & Kesimpulan \\
\hline $\begin{array}{l}\text { Masuk Menu } \\
\text { login }\end{array}$ & $\begin{array}{c}\text { Mengetikkan } \\
\text { Username dan/atau } \\
\text { password tidak } \\
\text { sesuai, kemudian } \\
\text { klik tombol Login }\end{array}$ & $\begin{array}{l}\text { Sistem akan } \\
\text { menolak dan } \\
\text { menampilkan pesan } \\
\text { "Username atau } \\
\text { Password yang anda } \\
\text { masukan salah" }\end{array}$ & Sesuai & Normal \\
\hline $\begin{array}{l}\text { Update data } \\
\text { donor }\end{array}$ & $\begin{array}{l}\text { Klik data donor yang } \\
\text { akan diupdate } \\
\text { kemudian, klik } \\
\text { 'Tombol' Update }\end{array}$ & $\begin{array}{l}\text { Data Berhasil } \\
\text { diupdate }\end{array}$ & Sesuai & Normal \\
\hline $\begin{array}{l}\text { Mengisi Form } \\
\text { Donor }\end{array}$ & Mengisi data & $\begin{array}{l}\text { Data berhasil } \\
\text { tersimpan }\end{array}$ & Sesuai & Normal \\
\hline $\begin{array}{c}\text { Mendaftar/regist } \\
\text { rasi }\end{array}$ & $\begin{array}{l}\text { Mengetikkan } \\
\text { username dan } \\
\text { pasword baru }\end{array}$ & $\begin{array}{l}\text { Data berhasil } \\
\text { tersimpan }\end{array}$ & Sesuai & Normal \\
\hline
\end{tabular}

\section{Operation and maintenance}

Setelah system diuji coba tahapan berikutnya adalah pendistribusian system. Dalam hal ini, system digunakan oleh kader posyandu kelurahan Bantarsoka sebagai administratornya dan ibu-ibu menyusui di lingkungan kelurahan tersebut sebagai anggotanya.

\section{Pembahasan}

Hasil dari penelitian ini adalah Sistem informasi pengelola Bank ASI berbasis website. Sistem tersebut berhasil dirancang dengan tampilan yang tertera pada gambar 3 sampai gambar 7. Gambar 3 merupakan halaman home user yang mengakses web Bank ASI. Agar tampilan terlihat menarik, menggunakan beberapa efek animasi dan tampilan dengan warnawarni yang cerah. Gambar 4 merupakan halaman login administrator. Pada halaman ini, menampilkan verifikasi username dan password akun administrator. Verifikasi ini sangat diperlukan, agar hanya seorang administrator web yang dapat mengubah konten.Gambar 5 adalah halaman home administrator. Pada halaman ini, administrator dapat mengolah konten web seperti pemblokiran pengguna, penambahan artikel, membaca pesan masuk. Gambar 6 merupakan halaman daftar pendonor yang tersedia beserta lokasi dan nomor kontak (Whatsapp, Telphone, email pendonor). Pada gambar 7, terdapat form pendaftaran untuk bergabung menjadi member aplikasi ini. Pendaftaran gratis, dan hanya orang yang terdaftar yang bisa mendonorkan ASI-nya.

Terdapat lima fungsi pada sistem informasi pengelola Bank ASI. Fungsi tersebut meliputi melihat stok ASI di web, registrasi, update data donor, mengisi form donor, dan rekap kegiatan donor. Fungis-fungsi tersebut dapat diakses oleh tiga aktor yaitu administrator, pendonor dan penerima ASI dengan masing-masing akses yang dimiliki. Pengujian dilakukan dengan black box testing. Skenario pengujian diantaranya adalah masuk menu login, update data donor, mengisi form donor, dan mendaftar/registrasi. Kasus pengujian yang diterapkan pada skenario pengujian diantaranya Mengetikkan Username 
dan/atau password tidak sesuai, kemudian klik tombol Login hasil yang diharapkan adalah Sistem akan menolak dan menampilkan pesan "Username atau Password yang anda masukan salah", kasus ke dua Klik data donor yang akan diupdate kemudian, klik 'Tombol' Update hasil yang diharapkan adalah data berhasil diupdate, kasus ketiga mengisi data hasil yang diharapkan adalah data berhasil tersimpan, dan kasus ke empat adalah mengetikkan username dan pasword baru hasil yang diharapkan adalah data berasil tersimpan. Dari hasil pengujian yang tertera pada tabel 1 menunjukan bahwa semua kasus pengujian sesuai dengan hasil yang diharapkan. Disimpulkan bahwa sistem berjalan normal.

\section{SIMPULAN}

Telah berhasil dibuat sistem informasi pengelola Bank ASI berbasis website yang berfungsi untuk memudahkan pendonor dan penerima ASI bertransaksi dalam berbagi ASI. Pendonor dan penerima terdata dengan baik dalam sistem sehingga memudahkan transaksi donor ASI sesuai dengan kriteria yang dibutuhkan. Dengan berbasis website memudahkan pengguna mengakses sistem informasi tersebut.

\section{REFERENSI}

Abdullah, R. D. P. (2017). Analisis Hukum Jual Beli Air Susu Ibu (ASI) Ditinjau dari Hukum Islam. Universitas Hasanudin.

Andri, A., \& Suyanto, S. (2020). Pengembangan Aplikasi Lelang Karet Berbasis Mobile Sebagai Pendukung Akses Informasi Lelang. Edumatic: Jurnal Pendidikan Informatika, 4(2), 85-94.

Apollonio, F. I., Basilissi, V., Callieri, M., Dellepiane, M., Gaiani, M., Ponchio, F., ... Scopigno, R. (2018). A 3D-centered information system for the documentation of a complex restoration intervention. Journal of Cultural Heritage, 29, 89-99.

Ayuningtyas, R. N. (2018). Perancangan aplikasi donor asi menggunakan pendekatan desain partisipatif. Skripsi. Universitas Katolik Parahyangan.

Egziabher, T. B. G., \& Edwards, S. (2013). the importance of breast milk for the baby's first life. Africa's Potential for the Ecological Intensification of Agriculture, 53(9), 16891699.

Fadhlurrahman, M., \& Capah, D. (2020). Aplikasi Penyewaan Lapangan Futsal Berbasis Web. Edumatic: Jurnal Pendidikan Informatika, 4(2), 30-39. https://doi.org/10.29408/edumatic.v4i2.2412

Fikawati, S., \& Syafiq, A. (2009). Penyebab Keberhasilan dan Kegagalan Praktik Pemberian ASI Eksklusif. Kesmas: National Public Health Journal, 4(3), 120-131. https://doi.org/10.21109/kesmas.v4i3.184

Ganney, P. S., Pisharody, S., \& Claridge, E. (2013). Software Engineering. In Clinical Engineering: A Handbook for Clinical and Biomedical Engineers. https://doi.org/10.1016/B978-0-12-396961-3.00009-3

Hakim, L., Gustina, S., Putri, S. F., \& Faudiah, S. U. (2020). Perancangan Chatbot di Universitas Proklamasi 45. Edumatic: Jurnal Pendidikan Informatika, 4(1), 91-100.

Jaya, T. S. (2018). Pengujian Aplikasi dengan Metode Blackbox Testing Boundary Value Analysis (Studi Kasus: Kantor Digital Politeknik Negeri Lampung). Jurnal Informatika Pengembangan IT (JPIT), 3(2), 45-46.

Kusrini, W., Fathurrahmani, F., \& Sayyidati, R. (2020). Sistem Pakar untuk Diagnosa Penyakit Ayam Pedaging. Edumatic: Jurnal Pendidikan Informatika, 4(2), 75-84.

Muntohar, A. (2020). Sistem Informasi Data Klien Berbasis Java Pada Kantor Notaris dan PPAT Arif. Edumatic: Jurnal Pendidikan Informatika, 4(2), 58-67. https://doi.org/10.29408/edumatic.v4i2.2515

Raj, J. S., \& Smys, S. (2019). Virtual structure for sustainable wireless networks in cloud 
services and enterprise information system. Journal of ISMAC, 1(03), 188-205.

Rizki, R., \& Mulyati, S. (2020). Implementasi One Time Password Menggunakan Algoritma SHA-512 Pada Aplikasi Penagihan Hutang PT. XHT. Edumatic: Jurnal Pendidikan Informatika, 4(1), 111-120.

Subur, W., Dian, A., \& Merry Tyas, A. (2012). Hubungan Pendidikan dan Pengetahuan Ibu tentang ASI Eksklusif dengan Sikap terhadap Pemberian ASI Eksklusif. Jurnal Kedokteran Muhammadiyah, 1(1), 25-19.

Suprapto, D. D. A., Fauziah, F., Fitri, I., \& Hayati, N. (2020). Pengembangan Aplikasi Sistem Informasi Smart Register Online Berbasis Android Menggunakan Algoritma BruteForce. Edumatic: Jurnal Pendidikan Informatika, 4(1), 47-56.

UNICEF. (2018). breastfeeding A Mother's Gift, for Every Child. Retrieved February 24, 2021, from ttp://www.unicef.org/indonesia/id/\%0Amedia_19265.html 